\title{
Self Regulation in Working Women: Cognitive Interference and Problem Solving
}

\author{
Dr. Baldev Singh Sandhu ${ }^{1}$, Dr. Yogita Sharma ${ }^{2} *$
}

\section{ABSTRACT}

The understanding of dynamics of self regulation in working women who on one hand are always under divergent pressures of performances and meet diverse kind of expectations on the other hand show relatively better volitional controls over their behavior, becomes important. This study examined the links between self regulation and cognitive functions in a sample of 318 working women. Cognitive functions were assessed through problem solving and cognitive interference. Results indicated that there is highly positive and significant association between self regulation and problem solving capacity $(\mathrm{P}<.01)$ and the capacity to handle cognitive interference $(\mathrm{P}<.01)$. Additional analysis demonstrated that women with sharp cognitive functions were high on self regulation as compared to women with disrupted cognitive functions.

Keywords: Self regulation, Cognitive interference, Problem solving, working women.

Self- regulation refers to individual's ability to set goals, planning activities, monitoring progress, controlling, and regulating their own cognitive activities and actual behaviour (Pintrich et al, 1993). Self-regulation is a broad concept. It includes both affective capacities - moods, feelings and emotions and cognitive capacities - beliefs, perceptions and knowledge. Learning and attainment are best understood when we acknowledge the interactions between affective and cognitive processes. Self-regulation also includes meta-cognitive skills - that is, understanding one's own cognitive skills, including memory, attention and problem solving. This enables an individual to make the best use of their knowledge and skills (Pressley, 1995).

In any domain of psychological functioning of the individual three interrelated components viz performance, knowledge acquisition and executive meta-components are largely influenced by cognitive functions. Cognitive skills are abilities that are used to learn, understand and integrate information in a meaningful way. Information that is learned cognitively is understood, not just memorized. There are many types of cognitive skill, and each requires specific set of skills.

\footnotetext{
${ }^{1}$ Dept. of Psychology, Punjabi University, Patiala, Punjab, India

${ }^{2}$ Human Reproduction Research Centre, Deptt. of Obst. \& Gynae, Safdarjung Hospital, New Delhi, India *Responding Author

(c) 2016 I B Sandhu, Y Sharma; licensee IJIP. This is an Open Access Research distributed under the terms of the Creative Commons Attribution License (http://creativecommons.org/licenses/by/2.0), which permits unrestricted use, distribution, and reproduction in any Medium, provided the original work is properly cited.
} 


\section{Self Regulation in Working Women: Cognitive Interference and Problem Solving}

Some examples of cognitive skills include memory, attention, perception and a wider category known as executive skills. Each of these skills can be further divided into specific mental operations that can be used in different situations. Cognitive skills are primarily employed to solve problems, perceive the world in a way that makes sense, and to learn new skills and information.

Researchers suggest that the acquisition of cognitive skill is affected not only by the quantity but by the quality of self-explanations given by the individual. The studies have found that while studying instructional materials particular characteristics of the self-explanations made by students correlated with the students' subsequent problem-solving ability. The high-performance students were found to use self-regulation strategies in constructing their explanations. When high performers studied the examples in the instruction, they typically connected example features to concepts that had been introduced in the text. (Chi, Bassok, Lewis, Reimann, \& Glaser, 1989;Pirolli \& Bielaczyc, 1989; Pirolli \& Recker, 1994; Duncan et al., 2007; Efklides et al., 1999; McClelland et al., 2000).)

Sanz be Acedo \& Iriarte, 2001, assessed the effects of the administration of package of activities, known as portfolio, on adolescents' cognitive functioning and self regulation of learning. Statistically significant differences were observed between the experimental and the control groups on measures of general intelligence, cognitive flexibility, metacognitive strategies $(\mathrm{P}<.01)$ Statistically significant gains were observed for the experimental group on measures of decision making problem solving and self regulation.

Sewell et.al, 1983, examined the relationships among self-regulatory behaviors, perceptions of social reinforcement from significant persons, and the problem-solving performance of black adolescents. The components of self-regulatory processes i.e self-reinforcement, self-evaluation and self-monitoring are highly interrelated. Subject's perception of neither positive nor negative social reinforcement was significantly related to problem-solving performance.

Thiede 1999, suggests that accuracy of metacognitive monitoring and self-regulation of study will affect test performance. He examined the relation between these variables in a multi-trial learning task. Regression analyses showed that monitoring accuracy and self-regulation were significantly related to test performance-greater monitoring accuracy and more effective selfregulation were associated with greater test performance.

Lazakidou,G. et.al, 2007, found that medium solvers group performed better than expert group in cooperative environments as compare to traditional. Moreover, findings advocate that learning environments which provide peer modeling may contribute to the development of self-regulatory skills in medium problem solvers. 
Pressley and McCormick (1995) have emphasized the role of self regulation in the problem solving of experts. Despite receiving high-quality formal trainings from other, experts had to become ultimately their own teachers in order to succeed. They had to learn to keep themselves on task and to guide their thinking through regulation of complex sequences of procedure that are combined and coordinated with prior knowledge. When prior knowledge did not fit into the current situation, experts made self regulatory adjustments that produced new knowledge, which was then available for future purposes. "Self-regulated thinking builds on itself with the selfregulated thinker always becoming a better thinker.” (Pressley \& McCormick, 1995).

Compton et. al (2011) in his study, tested the hypothesis that individual differences in cognitive control can predict individual differences in emotion regulation. Depression levels predicted daily affect and coping independent of cognitive control variables. The results support for an integrated conception of cognitive and emotional self-regulation.

\section{Hypotheses}

Women with sharp Cognitive Functions would be high on Self Regulation as compared to women with disrupted Cognitive Functions

\section{METHOD:}

Sample of the present study comprised of 318 married and working women, their age ranging between 30 to 45 yrs. All the subjects were working in different professions viz Schools, Colleges, Banks, Research, Consultancy Services, telecommunication, and IT Sector.

The selection of the sample was incidental as only those subjects were taken who gave their consent participation in the study and who had been in the job for at least 5 years or more.

\section{Tools used are -}

1. The Problem Solving Inventory (Heppner, 1988)

2. The stroop neuropsychological screening test (Trenery, Crosson, Deboe, Leber, 1989)

3. The Self Regulation Questionnaire (Brown, Miller \& Lawendowski, 1999)

\section{Statistical Analyses}

Data obtained for present study pertaining to variables of self regulation, and cognitive functions was statistical analyzed and Means, Standard Deviations, $\mathrm{t}$-test and Pearson's product moment correlation were applied to test the hypotheses 
RESULTS \& DISCUSSION

\begin{tabular}{|c|l|c|c|}
\hline Sr. No & \multicolumn{1}{|c|}{ Variables } & Mean & Std. Deviation \\
\hline 1 & REC & 32.54 & 4.93 \\
\hline 2 & EVA & 28.65 & 3.62 \\
\hline 3 & TRI & 29.57 & 3.94 \\
\hline 4 & SEA & 32.94 & 4.7 \\
\hline 5 & FOR & 30.03 & 4.51 \\
\hline 6 & IMP & 30.72 & 4.76 \\
\hline 7 & ASS & 31.1 & 4.21 \\
\hline 8 & SRQ_Total & 215.55 & 21.91 \\
\hline 9 & CON & 29.1 & 7.83 \\
\hline 10 & AA & 45.48 & 8.51 \\
\hline 11 & PC & 16.39 & 4.52 \\
\hline 12 & Prsl_Total & 90.97 & 17.16 \\
\hline 13 & SC_W & 98.78 & 11.25 \\
\hline
\end{tabular}

The means for (various)indices of self regulation namely Receiving (REC), Evaluating (EVA), Triggering (TRI), Searching (SEA), Formulating (For), Implementing (IMP), Assessing (ASS) and Total score for Self Regulation Questionnaire are 32.54, 28.65, 29.57, 32.94, 30.03, 30.72, 30.10 and 215.55 and standard deviation for these indices are 4.92, 3.62, 3.94, 4.69, 4.50, 4.76, 4.21 and 21.91 respectively.

For problem solving, the means and SD's for Problem solving confidence (CON) are 29.10 and 7.83, for Approach Avoidance Style (AA) 45.48 \& 8.51, for Personal Control (PC) 16.39 \& 4.52, and for Problem solving Total 90.97 \& 17.16 respectively. Mean value of Stroop effect (SC_W) is 98.75 and $\mathrm{SD}$ is 11.25 .

women with sharp cognitive functions would be high on self regulation as compared to women with disrupted cognitive functions, two groups of subjects with sharp cognitive functions ( $n=36)$ and disrupted cognitive functions $(n=46)$ were selected. Criteria for selecting sharp cognitive functions subjects used was their low score on problem solving ability (X- $1 / 2$ SD, 82.5) and low score on stroop test (score of 98 and below the cut off used as per manual). For disrupted cognitive functions, selection criteria was high score on problem solving (i.e. $\mathrm{M}+1 / 2$ SD i.e.98.5) and high score in stroop test (score of 99 and above as per normal). The means, standard deviation and t-ratio are shown in table: 
Self Regulation in Working Women: Cognitive Interference and Problem Solving

Table showing Comparison of individuals with sharp and disrupted cognitive functioning on Self Regulation.

\begin{tabular}{|l|l|l|l|l|l|}
\hline \multirow{2}{*}{ Variables } & \multicolumn{3}{l}{ Cognitive Functioning } & \multirow{2}{*}{ t-ratios } \\
\cline { 2 - 6 } & \multicolumn{2}{|l|}{ Sharp(n=36) } & \multicolumn{2}{l|}{ Disrupted(n=46) } & \\
\hline & Means & SD & Means & SD & \\
\hline REC & 34.69 & 4.30 & 30.57 & 4.88 & $4.00^{* *}$ \\
\hline EVA & 28.72 & 3.11 & 28.17 & 4.05 & 0.67 \\
\hline TRI & 31.42 & 3.30 & 29.09 & 3.86 & $2.89^{* *}$ \\
\hline SEA & 35.03 & 3.83 & 31.48 & 4.19 & $3.95^{* *}$ \\
\hline FOR & 32.47 & 4.83 & 27.50 & 3.18 & $5.60^{* *}$ \\
\hline IMP & 33.58 & 3.98 & 28.22 & 3.88 & $6.15^{* *}$ \\
\hline ASS & 32.94 & 3.73 & 30.48 & 4.12 & $2.80^{* *}$ \\
\hline Total SR & 228.86 & 19.14 & 205.50 & 18.91 & $5.52^{* *}$ \\
\hline
\end{tabular}

**Significant at .01 level

t-ratio for the composite index of self regulation was found to be 5.52 which is significant at .01 level. Except for evaluation subscale of self regulation questionnaire, t-ratio for all the other subscale (viz receiving, 4.0, triggering, 2.89, searching, 3.95, formulating, 5.60, Implementing, 6.15, and assessing, 2.80.) are significant at .01 level.

Mean scores of self regulation for subjects with sharp and disrupted cognitive functions clearly reveal the superior self regulation capacity of those who showed better cognitive functioning in terms of their ability to solve problems, lesser cognitive interference while performing cognitive actives. Those subjects who had relatively poor cognitive functioning were found to have relatively lower degree of self regulation capacity. Results are in line with the statement of Sanz de Acedo \& Iriarte, 2001; Compton, 2011 \& Pressley \& McCormick 1995, that higher the self regulation, better the problem solving ability and lesser the cognitive interference.

Construct of self regulation involves better information input, its effective use than self evaluation \& choosing better alternative then their implementation and outcome evaluation. All these attributes when in operation do favor effective performance tasks which require the use of cognitive skills.

As the direction of scoring of tests of problem solving (PSI) and cognitive interference (stroop) are in the reverse direction, negative value of coefficient of correlation is indicative of positive association. 


\begin{tabular}{|c|c|c|c|c|c|c|c|c|c|c|c|c|c|}
\hline & $\begin{array}{l}\frac{\pi}{\mathrm{M}} \\
\mathrm{S}\end{array}$ & $\underset{>}{\stackrel{T}{2}}$ & 븜 & $\stackrel{\substack{M T \\
D}}{D}$ & $\begin{array}{l}\text { Ō } \\
\text { O্ঠ }\end{array}$ & 家 & $\begin{array}{l}\vec{D} \\
\sim\end{array}$ & $\begin{array}{l}\stackrel{-}{0} \\
\stackrel{D}{D} \\
0 \\
0 \\
0\end{array}$ & 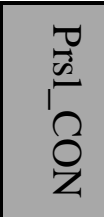 & 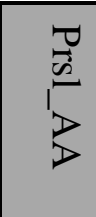 & $\begin{array}{l}\frac{\pi}{\sqrt[n]{n}} \\
\frac{1}{5}\end{array}$ & 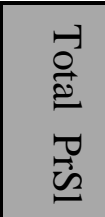 & ${ }^{\infty}$ \\
\hline REC & 1.00 & & & & & & & & & & & & \\
\hline EVA & 0.32 & 1.00 & & & & & & & & & & & \\
\hline TRI & 0.48 & 0.15 & 1.00 & & & & & & & & & & \\
\hline SEA & 0.65 & 0.30 & 0.52 & 1.00 & & & & & & & & & \\
\hline FOR & 0.58 & 0.22 & 0.36 & 0.47 & 1.00 & & & & & & & & \\
\hline IMP & 0.65 & 0.13 & 0.36 & 0.54 & 0.55 & 1.00 & & & & & & & \\
\hline ASS & 0.51 & 0.35 & 0.33 & 0.51 & 0.25 & 0.40 & 1.00 & & & & & & \\
\hline Total SRQ & 0.86 & 0.47 & 0.64 & 0.82 & 0.71 & \begin{tabular}{|l|l|}
0.76 \\
\end{tabular} & 0.67 & 1.00 & & & & & \\
\hline Prsl_CON & -0.36 & -0.17 & -0.28 & -0.40 & -0.28 & \begin{tabular}{|l|}
-0.34 \\
\end{tabular} & -0.34 & -0.44 & 1.00 & & & & \\
\hline Prsl_AA & -0.44 & -0.20 & -0.39 & -0.44 & -0.34 & \begin{tabular}{|l|}
-0.38 \\
\end{tabular} & -0.34 & -0.52 & 0.68 & 1.00 & & & \\
\hline Prsl_PC & -0.30 & -0.04 & -0.14 & -0.23 & -0.34 & \begin{tabular}{|l|}
-0.32 \\
\end{tabular} & -0.19 & -0.32 & 0.29 & 0.37 & 1.00 & & \\
\hline Total PrSl & -0.46 & -0.19 & -0.36 & -0.46 & -0.39 & -0.43 & -0.38 & -0.54 & 0.87 & 0.91 & 0.58 & 1.00 & \\
\hline SC_W & -0.40 & -0.16 & -0.32 & -0.41 & -0.35 & \begin{tabular}{|l|}
-0.39 \\
\end{tabular} & -0.33 & -0.48 & 0.84 & 0.88 & 0.58 & \begin{tabular}{|l|}
0.97 \\
\end{tabular} & 1.00 \\
\hline
\end{tabular}

Abbreviations

$\begin{array}{llll}\text { REC } & \text { Receiving } & \text { Total SRQ } & \text { Self Regulation Questionnaire } \\ \text { EVA } & \text { Evaluating } & \text { Prsl_CON } & \text { Problem Solving Confidence } \\ \text { TRI } & \text { Triggering } & \text { Prsl_AA } & \text { Approach Avoidance Style } \\ \text { SEA } & \text { Searching } & \text { Prsl_PC } & \text { Personal Control } \\ \text { FOR } & \text { Formulating } & \text { Total PrSl } & \text { Total Problem Solving } \\ \text { IMP } & \text { Implementing } & \text { SC_W } & \text { Stroop color-word test } \\ \text { ASS } & \text { Assessing } & & \end{array}$

Value of coefficient of correlation between composite indices of self regulation and measures of problem solving and cognitive interference for total group $(\mathrm{n}=318)$ were $-.54(\mathrm{P}<.01),-.48$ $(\mathrm{p}<.01)$ respectively.

The correlational values indicate that there is a high positive and significant Correlation between self regulation and problem solving capacity $(\mathrm{r}=-.54, \mathrm{P}<.01)$ and the capacity to handle cognitive interference $(\mathrm{r}=-.48, \mathrm{P}<.01)$. Overall picture emerged from correlation matrics reveals there is a positive and highly significant correlation between self regulation and cognitive functions i.e. the higher the self regulation capacity, the sharper the two components of cognitive functioning. Similar findings reported by Lazakidou,G. et al, 2007, Thiede 1999 \& Compton 2011. 


\section{Self Regulation in Working Women: Cognitive Interference and Problem Solving}

Baumeister, Dewall, Ciarocco, \& Twenge, J.M. (2005) looked at any cognitive impairment as a result of self regulation deficits. Pintrich, \& Garcia, 1999 reported that mastery goal orientation is positively related to cognitive strategies. In this sense close association between self regulation and cognitive functions tend to go hand in glove which is established by the present results.

\section{BIBLIOGRAPHY}

Chi, M. T. H., Bassok, M., Lewis, M., Reimann, P., \& Glasser, R. (1989). Self-explanations: How students study and use examples in learning to solve problems. Cognitive Science, 13, 145-182.

Compton RJ, Arnstein D, Freedman G, Dainer-Best J, Liss A, Robinson M.D. (2011) Neural and behavioral measures of error-related cognitive control predict daily coping with stress. Emotion. 11(2), 379-90

Duncan, G. J., Dowsett, C. J., Claessens, A., Magnuson, K., Huston, A. C., Klebanov, P., et al. (2007). School readiness and later achievement. Developmental Psychology, 43, 1428-1446.

Efklides, A., Samara, A., \& Petropoulou, M. (1999). Feeling of difficulty: An aspect of monitoring that influences control. European Journal of Psychology of Education, 14, 461-476.

Heppner, P. P. (1988). The Problem Solving Inventory. Palo Alto, CA: Consulting Psychologists Press.

McClelland, M. M., Morrison, F. J., \& Holmes, D. L. (2000). Children at risk for early academic problems: The role of learning-related social skills. Early Childhood Research Quarterly, 15, 307-329.

Pintrich, P.R., Smith D.A.F., Garcia T. \& McKeachie W.J. (1993). Reliability and predictive validity of the motivated strategies for learning questionnaire (MSLQ), Educational and Psychological Measurement, 53, 801-803.

Pirolli, P. \& Bielaczyc, K. (1989). Empirical analyses of self-explanation and transfer in learning to program. In Proceedings of the 11th Annual Conference of the Cognitive Science Society, Hillsdale, NJ: Lawrence Erlbaum.

Pirolli, P. \& Recker, M. (1994). Learning strategies and transfer in the domain of programming. Cognition and Instruction 12, 235-275.

Pressley, M. (1995). More about the development of self-regulation: Complex, long-term, and thoroughly social. Educational Psychologist, 30, 207-212.

Sanz de Acedo Lizarraga, M. L., Iriarte Iriarte, M. D. (2001). Enhancement of Cognitive Functioning and Self-Regulation of Learning. The Spanish Journal of Psychology, 4(1), 55-64.

Sewell, T E · Chandler, M E · Smith, R (1983). Self-regulation and external reinforcement in problem-solving strategies of black adolescents. Journal of clinical psychology 39(1), 39-45.

Thiede, K. W. (1999). Rereading improves comprehension monitoring. Paper presented at the annual meeting of the American Educational Research Association, Montreal, Canada.

Trenerry, M. R., Crosson, B., DeBoe, J., \& Leber, W. R. (1989). The Stroop Neuropsychological Screening Test. Odessa, FL: Psychological Assessment Resources.

How to cite this article: B Sandhu, Y Sharma (2016), Self Regulation in Working Women: Cognitive Interference and Problem Solving, International Journal of Indian Psychology, Volume 3, Issue 3, No. 8, DIP: 18.01.147/20160303, ISBN: 978-1-365-12176-0 